\title{
Pityriasis rosea in a patient with retrovirus infection: a reply
}

\author{
Giulia Ciccarese, Aurora Parodi, Francesca Drago, Astrid Herzum, Francesco Drago
}

Department of Dermatology, IRCCS A.O.U. San Martino-IST, Genoa, Italy

Adv Dermatol Allergol 2018; XXXV (1): 116-117 DOI: https://doi.org/10.5114/ada.2018.73172

We read with interest the paper from Neneman et al. [1] about a case of pityriasis rosea (PR) in a patient with retrovirus infection and would like to make some comments. At the physical examination of their patient, the authors did not observe the mucous membranes to detect possible oropharyngeal lesions associated with PR. Indeed, although they stated that in PR "no eruptions are observed on the mucous membranes", studies have shown that they may be observed in both Caucasian and dark skinned people [2]. Furthermore, we have recently reported that among 527 Caucasian patients with PR who between 2003 and 2016 attended the Dermatology Clinic of Genoa University, painless oropharyngeal lesions (enanthems) were observed in 149 (28\%) cases. The most frequent lesions had petechial and maculopapular patterns [3]. Interestingly, in our series, these enanthems were frequently associated with forms of PR different from the classic one: persistent [4], relapsing [5], pediatric PR [6] and PR during pregnancy [4, 7].

As regards the laboratory investigations, despite large amounts of evidence showing that PR is associated with the systemic endogenous reactivation of human herpesvirus (HHV)-6 and 7 [2], the authors did not perform serology for HHV-6/7 in their patient nor measure the HHV-6/7 DNA load in plasma by quantitative real-time polymerase chain reaction (PCR), the latter considered as a marker of active viral infection [8].

Regarding the etiology of PR, the authors stated that it is unclear [1]. However, a large number of studies have shown a causal role for HHV-6 and HHV-7 systemic endogenous reactivation in the pathogenesis of PR. In fact, HHV-6 and HHV-7 DNA were found in plasma and skin lesions of PR patients by real-time PCR and HHV-6 mRNA expression and specific antigens were found by immunohistochemistry in their skin lesions. Moreover, herpesvirus virions in various stages of morphogenesis were detected by electron microscopy in skin lesions and in the supernatant of co-cultured peripheral blood mono- nuclear cells (PBMCS) from PR patients [2]. The primary infection by HHV-6 and/or HHV-7 usually occurs in early childhood and may be asymptomatic, or may cause exanthema subitum (roseola infantum) or a febrile illness without any rash rarely accompanied by convulsions [2]. Afterwards they establish a long-life latent infections in different cells and organs, including monocytes, bonemarrow progenitors cells and salivary glands. The mechanisms that may trigger reactivation of these viruses and therefore the occurrence of PR are poorly understood, but the magnitude of the latent viral population and the presence of latency-associated transcripts seem to be important factors, along with psychologically stressful events, trauma, fever and states of immunosuppression, such as pregnancy and UV exposure [2].

Regarding epidemiology of PR, we agree with the authors on the higher prevalence of PR in children, young adults, pregnant women and immunocompromised patients, compared to the general population, as previously described [2]. However, unlike the statement of Neneman et al. [1], in our experience of more than 600 PR patients since January 2003, there is no statistically significant prevalence of PR in a specific season of the year nor family tendency of developing the disease [2]. As regards the duration of PR, we agree with the authors that besides the typical duration of 6-8 weeks, cases of shorter and longer durations are possible. In our experience, the duration of PR was shorter in children (average duration: 16 days) compared to adults (average duration: 45 days) [6]. We also described 12 cases of PR lasting longer than 12 weeks, defining these forms as "persistent PR". Although the authors suggested that among human immunodeficiency virus (HIV) infected patients the PR course is usually long, our series of persistent PR cases did not include any HIV-infected patients [4].

Neneman et al. [1] did not specify whether their HIVpositive patient was taking an antiretroviral therapy and, if so, how long the patient was taking the drug. Indeed,

Address for correspondence: Giulia Ciccarese, Department of Dermatology IRCCS A.O.U. San Martino-IST, Largo Rosanna Benzi 10, 16132 Genova, Italy, phone: +39 0105555750, fax: +39 0105556509, e-mail: giuliaciccarese@libero.it Received: 20.07.2017, accepted: 25.07.2017. 
the pathogenesis of PR in such cases might resemble the particular immune condition that has been described in the immune reconstitution inflammatory syndrome (IRIS), typically affecting patients with HIV infection upon initiation of combination antiretroviral therapy. Indeed, IRIS is associated with the reactivation of latent infections, triggered by the immunological changes. Upon initiation of combination antiretroviral therapy, recovery of cellular immunity triggers inflammation against a pre-existing latent infection or antigen that causes paradoxical worsening of the clinical disease. Although the immune pathogenesis of IRIS still needs to be determined, reactivation of latent infections, including HHVs and specifically of HHV-6, has already been described $[9,10]$.

Further studies would be helpful to assess the prevalence and the features of PR (in terms of duration, severity of symptoms, morphology, number and distribution of skin lesions) among HIV infected patients, before, at the onset and during maintenance of antiretroviral therapies.

\section{Conflict of interest}

The authors declare no conflict of interest.

\section{References}

1. Neneman A, Mikiel D, Adamski Z, Bowszyc-Dmochowska M. Pityriasis rosea in a patient with retrovirus infection and a history of syphilis and positive results of infection with hepatitis A virus, hepatitis B virus and hepatitis C virus. Adv Dermatol Allergol 2017; 34: 276-8.

2. Drago F, Broccolo F, Rebora A. Pityriasis rosea: an update with a critical appraisal of its possible herpesviral etiology. J Am Acad Dermatol 2009; 61: 303-18.

3. Ciccarese G, Broccolo F, Rebora A, et al. Oropharyngeal lesions in pityriasis rosea. J Am Acad Dermatol 2017; 77: 833837.e4.

4. Drago F, Broccolo F, Ciccarese G, et al. Persistent pityriasis rosea: an unusual form of pityriasis rosea with persistent active HHV-6 and HHV-7 infection. Dermatology 2015; 230: 23-6.

5. Drago F, Ciccarese G, Rebora A, Parodi A. Relapsing pityriasis rosea. Dermatology 2014; 229: 316-8.

6. Drago F, Ciccarese G, Broccolo F, et al. Pityriasis rosea in children: clinical features and laboratory investigations. Dermatology 2015; 231: 9-14.

7. Drago F, Broccolo F, Javor S, et al. Evidence of human herpesvirus- 6 and -7 reactivation in miscarrying women with pityriasis rosea. J Am Acad Dermatol 2014; 71: 198-9.

8. Broccolo F, Drago F, Cassina G, et al. Selective reactivation of human herpesvirus 6 in patients with autoimmune connective tissue diseases. J Med Virol 2013; 85: 1925-34.

9. Drago F, Javor S, Bruzzone L, et al. Pityriasis rosea in a hepatitis B-positive patient treated with pegylated interferon alpha2a: report of a case and review of the literature. Dermatology 2014; 228: 10-3.

10. Drago F, Broccolo F, Agnoletti A, et al. Pityriasis rosea and pityriasis rosea-like eruptions. J Am Acad Dermatol 2014; 70: 196. 